Earth Interactions • Volume 20 (2016) - Paper No. 15 • Page 1

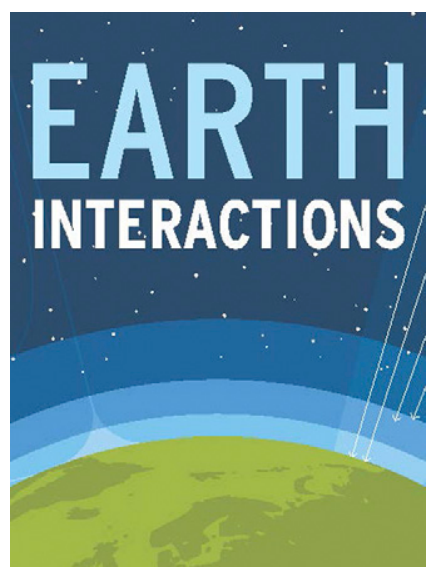

Copyright $\odot$ 2016, Paper 20-015; 51196 words, 7 Figures, 0 Animations, 1 Tables.

http://EarthInteractions.org

\title{
Spatial and Temporall Patterns of Cloud Cover and Fog Inundation in Coastal California: Ecologicall Implications ${ }^{\curvearrowright}$
}

Bharat Rastogi, ${ }^{+, \#, @ ~ A . ~ P a r k ~ W i l l i a m s, ~}{ }^{\text {\& }}$ Douglas T. Fischer,**, ${ }^{*},++$ Sam F. Iacobellis, ${ }^{\#}$ Kathryn McEachern, ${ }^{@}$ Leila Carvalho, ${ }^{@}$ Charles Jones, ${ }^{@}$ Sara A. Baguskas, ${ }^{\& \&, @ ~ a n d ~ C h r i s t o p h e r ~ J . ~ S t i l l ~}{ }^{\#, @ ~}$

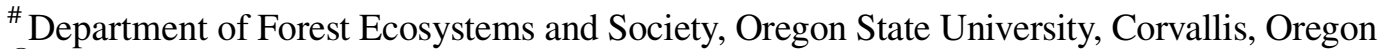

${ }^{\circledR}$ Department of Geography, University of California, Santa Barbara, Santa Barbara, California

${ }^{\&}$ Lamont-Doherty Earth Observatory of Columbia University, Palisades, New York ** Strategic Environmental Consulting, ARCADIS, Santa Barbara, California

${ }^{++}$Ronin Institute, Santa Barbara, California

\#\# Scripps Institution of Oceanography, University of California, San Diego, La Jolla, California ${ }^{\circledR}$ U.S. Geological Survey-Western Ecological Research Center, Channel Islands Field Station, Ventura, California

\&\& Department of Environmental Studies, University of California, Santa Cruz, Santa Cruz, California

Received 29 May 2015; in final form 15 January 2016

O) Supplemental information related to this paper is available at the Journals Online website: http://dx.doi.org/10.1175/EI-D-15-0033.s1.

${ }^{+}$Corresponding author address: Bharat Rastogi, Department of Forest Ecosystems and Society, Oregon State University, 321 Richardson Hall, Corvallis, OR 97331.

E-mail address: bharat.rastogi@oregonstate.edu

DOI: 10.1175/EI-D-15-0033.1 
Earth Interactions - Volume 20 (2016) - Paper No. 15 • Page 2

\begin{abstract}
The presence of low-lying stratocumulus clouds and fog has been known to modify biophysical and ecological properties in coastal California where forests are frequently shaded by low-lying clouds or immersed in fog during otherwise warm and dry summer months. Summer fog and stratus can ameliorate summer drought stress and enhance soil water budgets and often have different spatial and temporal patterns. Here, this study uses remote sensing datasets to characterize the spatial and temporal patterns of cloud cover over California's northern Channel Islands. The authors found marine stratus to be persistent from May to September across the years 2001-12. Stratus clouds were both most frequent and had the greatest spatial extent in July. Clouds typically formed in the evening and dissipated by the following early afternoon. This study presents a novel method to downscale satellite imagery using atmospheric observations and discriminate patterns of fog from those of stratus and help explain patterns of fog deposition previously studied on the islands. The outcomes of this study contribute significantly to the ability to quantify the occurrence of coastal fog at biologically meaningful spatial and temporal scales that can improve the understanding of cloud-ecosystem interactions, species distributions, and coastal ecohydrology.
\end{abstract}

KEYWORDS: Circulation/dynamics; Atmosphere-ocean interaction; Cloud cover; Atmosphere/ocean structure/phenomena; Fog; Vegetation; Observational techniques and algorithms; Radiosonde observations; Remote sensing

\title{
1. Introduction
}

Low-lying stratocumulus clouds and fog have been known to modify biophysical and ecological properties in a variety of ecosystems in differing climates. These include montane cloud forests in the tropics, which are dependent on frequent and prolonged immersion in the cloud layer (Still et al. 1999), as well as in temperate regions such as the Appalachian Mountains in northeastern America, where the shift from low elevation deciduous to high elevation coniferous forests is thought to be controlled by the height of the cloud base (Kupfer and Cairns 1996). Cloud cover and fog might be especially important in Mediterranean coastal climate regions, where forests are frequently shaded by low-lying clouds or immersed in fog during summer (Dawson 1998; Cereceda et al. 2008; Garreaud et al. 2008). These regions are associated with high species richness and biodiversity and include the forests of California, Chile, southwestern Australia, and southern Africa. Coastal California is home to numerous endemic plant species; many of these are relictual endemic species, meaning that they were more widespread during cooler and wetter climates in the past. Examples include coastal redwoods (Sequoia sempervirens D. Don), which were once found several hundreds of kilometers inland and now persist only in narrow bands along generally foggy coastlines. The decline in forest ranges and boundaries is attributed to warming since the Last Glacial Maximum around $25 \mathrm{ka}$ (Noss 1999).

The dominant feature that drives the summertime climate along much of North America's western coast is the Pacific high, which promotes subsidence of dry, warm air over the eastern margin of the North Pacific. Inland, daytime surface heating creates a region of low pressure. This ocean-land pressure gradient drives north-northwesterly winds along the coast and upwelling of relatively cool coastal water. Large-scale subsidence of warm, dry air from the Pacific high interacts with 
Earth Interactions - Volume 20 (2016) • Paper No. 15 • Page 3

locally cool sea surface temperatures (SSTs) during summer to create a persistent atmospheric temperature inversion that caps a cool and humid marine layer generally less than $1 \mathrm{~km}$ thick (Leipper 1994; Dorman and Winant 2000; Iacobellis et al. 2009; Johnstone and Dawson 2010; Iacobellis and Cayan 2013). Marine stratus clouds develop beneath the upper boundary of this marine layer and often intersect with Earth's surface, particularly in coastal mountain areas. Coastal ranges that rise above the height of the base of the temperature inversion prevent inland penetration of the marine layer, and thus the "fog belt" is a narrow band running along the coastline. While there are different definitions of fog, for the purpose of this study it is defined as cloud intercepted by the land.

Low-lying stratus and fog have several important ecological impacts in coastal California. During warm and dry summers, cloud shading reflects incoming solar radiation, thereby reducing air and leaf temperatures, along with potential evapotranspiration (Fischer et al. 2009). Fog can further decrease drought stress by adding water to the ecosystem through fog drip, which is the process of droplets coalescing on leaves and dripping down to the surface (Carbone et al. 2013; Fischer et al. 2009). Fog drip is shown to be an important water source for more shallowly rooted sapling trees (Baguskas et al. 2016), which has important implications for the population dynamics of drought-sensitive species growing in a fog-influenced ecosystem. In addition, leaf wetting often results in direct uptake of water by plants, a mechanism known as foliar uptake (Dawson 1998; Burgess and Dawson 2004; Limm et al. 2009; Eller et al. 2013). In addition, fog drip may also influence carbon cycling via impacts on soil respiration (Carbone et al. 2011) as well as enhancing photosynthetic rates (Carbone et al. 2013) and tree growth (Williams et al. 2008). At the landscape level, summer cloud-cover frequency was found to be the most important environmental predictor for drought-induced tree mortality in a coastal pine forest (Baguskas et al. 2014).

Remote sensing can be used as an important tool to study spatial and temporal patterns of marine stratus (Gultepe et al. 2007; Koračin et al. 2014). Researchers have successfully used the Moderate Resolution Imaging Spectroradiometer (MODIS) on NASA's Terra and Aqua satellite platforms to study stratus events (Bendix et al. 2006; Deng et al. 2006; Chaurasia et al. 2011) as well as establish longer-term patterns of stratus frequency (Fischer et al. 2009; Williams 2009; Baldocchi and Waller 2014). However, the low temporal resolution of polar satellites such as MODIS (two images per day) inhibits characterization of how stratus moves across the landscape at finer temporal scales. Geostationary satellites like the National Oceanic and Atmospheric Administration (NOAA)'s Geostationary Operational Environmental Satellite (GOES) have also been used extensively to study fog (Ellrod 1995; Cereceda et al. 2008; Iacobellis and Cayan 2013). While GOES provides higher temporal resolution (half-hourly data), coarse spatial resolution limits its use in understanding interactions between stratus and vegetation, especially in areas with high topographic variation. Moreover, while satellite imagery can be used to detect the presence of stratus, it cannot typically provide information about the height of the cloud base, making it difficult to identify the presence of fog. A commonly used proxy for estimating low-lying stratus frequency is via point measurements of cloud-base heights, collected at airports (Williams et al. 2008; Johnstone and Dawson 2010; Schwartz et al. 2014; Williams et al. 2015). However, these data do not provide information on the 
Earth Interactions • Volume 20 (2016) • Paper No. 15 • Page 4

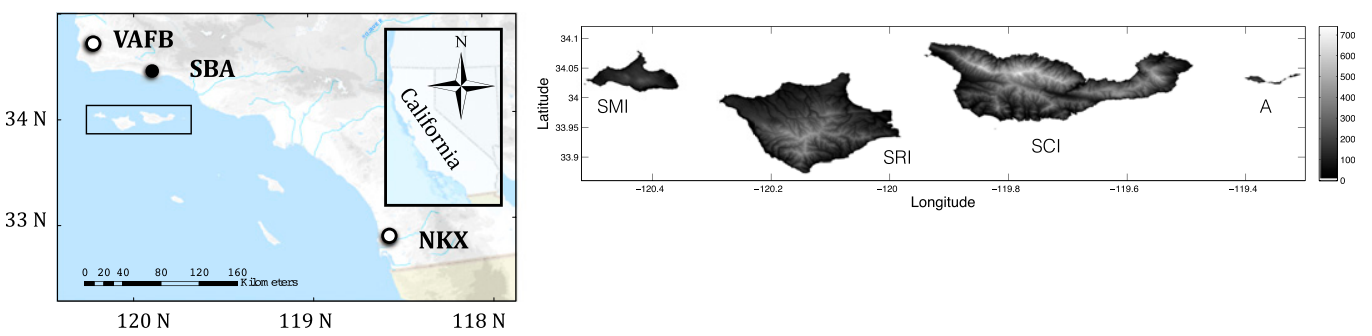

Figure 1. (a) Location of the northern Channel Islands of California. White circles represent location of radiosonde observations (VAFB and NKX), while black circle shows the location of cloud-base height measurements from SBA. (b) A DEM of the four islands labeled as San Miguel (SMI), Santa Rosa (SRI), Santa Cruz (SCl), and Anacapa (A).

spatial patterns of stratus and can be inaccurate when extrapolated because of localization effects.

In this study, we used GOES satellite imagery to understand the spatial and temporal patterns of cloud cover from diurnal to interannual scales. We also present a new method to downscale GOES imagery to spatial scales relevant for studying stratus-vegetation interactions by combining satellite imagery with airport cloud height information and a digital elevation model (DEM). The downscaling technique allows for characterizing when stratus clouds intersect with Earth's surface as fog.

\section{Methods}

\subsection{Site description}

This study was conducted in the northern Channel Islands off the coast of California, separated from the mainland by the Santa Barbara Channel, approximately $30 \mathrm{~km}$ south of Santa Barbara (Figure 1a). The northern Channel Islands comprise four islands, from west to east, San Miguel, Santa Rosa, Santa Cruz, and Anacapa (SMI, SRI, SCI, and A in Figure 1b), that are clustered together, each no farther than $10 \mathrm{~km}$ from the other. The four islands are located in a transition zone where cooler northern waters from the California Current meet warmer southern waters from the California Countercurrent (Otero and Siegel 2004).

Like the mainland, the northern Channel Islands experience a Mediterranean climate characterized by cool, wet winters and warm, dry summers that are marked by the presence of marine stratus. Precipitation records on Santa Cruz Island begin in the early 1900s and indicate that mean annual precipitation is approximately $410 \mathrm{~mm}$, and over $90 \%$ of this occurs during November-April with much inter- and intravariability in timing and magnitude (Fischer et al. 2009). On the two bigger islands (Santa Cruz and Santa Rosa), climate can vary dramatically. The central valley on Santa Cruz Island experiences a more continental climate compared to areas on the coast (Junak et al. 1995), and higher elevations (highest peak is $740 \mathrm{~m}$ ) receive considerably more precipitation than low elevations (Fischer et al. 2009). 
Earth Interactions • Volume 20 (2016) • Paper No. 15 • Page 5

Table 1. Datasets used in this study.

\begin{tabular}{llll}
\hline \multicolumn{1}{c}{ Data source } & \multicolumn{1}{c}{ Spatial resolution } & Temporal resolution & \multicolumn{1}{c}{ Temporal range } \\
\hline GOES imagery & $\sim 1 \mathrm{~km}\left(0.01^{\circ}\right)$ & $30 \mathrm{~min}$ & $2001-12$ \\
Airborne LiDAR DEM & $1 \mathrm{~m}$ & - & 2009 \\
Ceilometer data & Point measurement at SBA & Hourly & $1996-2012$ \\
Radiosonde & $\begin{array}{c}\text { Point measurements } \\
\text { at VAFB and NKX }\end{array}$ & $\begin{array}{c}\text { Twice daily at 0400 } \\
\text { and 1600 PST }\end{array}$ & 1965-present \\
Environmental data & Weather stations on SCI & 15 min & 2002-present (site specific) \\
\hline
\end{tabular}

Each island features a unique assemblage of vegetative communities determined by the climate and presence of microhabitats that are influenced by topography, soil characteristics, and proximity to the coast, among other factors. San Miguel Island is most exposed to the open ocean resulting in high north-northwesterly winds and frequent fog. This island is primarily a plateau with a median elevation of $104 \mathrm{~m}$ and is home to low-growing coastal scrub. Santa Rosa and Santa Cruz Islands have greater biological diversity owing to bigger size, complicated topography, and closer proximity to the mainland. These islands are more often sheltered from high winds by the Southern Californian Bight. Santa Rosa Island harbors a stand of Santa Rosa Island Torrey pine (Pinus torreyana Carr. ssp. insularis Haller), an extremely rare and relictual endemic species. Santa Cruz Island is the largest island, with high topographic variability that supports a wide variety of plant communities, many of which are drought tolerant. Frequent drought events pose challenges for Santa Cruz Island's only pine species, Bishop pine (Pinus muricata D. Don). There are some smaller island populations of this species on Guadalupe Island off the coast of northern Baja California, but Santa Cruz Island is home to the southernmost large population; the vast majority of this species' distribution lies on the mainland California coast hundreds of kilometers to the north. Anacapa is the smallest island and, like San Miguel, supports low-growing scrub that includes regional endemics such as the succulent giant coreopsis (Leptostyne gigantea) and live forevers (Dudleya spp.; Moody 2000).

\subsection{Datasets and processing}

A description of the datasets used in this study is shown in Table 1.

\subsubsection{Albedo data from GOES}

Satellite imagery was used to detect the presence of cloud cover throughout the study region. Imagery used in this study was collected by GOES-9, GOES-10, GOES-11, and GOES-15 satellites during 1 May-30 September of 2001-12 and obtained from the NOAA Comprehensive Large Array-Data Stewardship System (CLASS; available at www.nsof.class.noaa.gov) and the University of Wisconsin Space Science and Engineering Center. For details regarding GOES postlaunch calibration, readers are referred to Iacobellis and Cayan (2013) and references therein. GOES provides imagery at 30-min temporal resolution and is used for weather forecasting, storm tracking, and meteorology research. GOES imagery is available for a range of wavelength bands, and visible bands were used instead of IR bands because of their significantly higher spatial resolution $(1$ and $4 \mathrm{~km}$, 
Earth Interactions • Volume 20 (2016) • Paper No. 15 • Page 6

respectively). Moreover, clouds can be challenging to distinguish from the ocean using the GOES IR channel, as cloud-top temperatures are often similar to ocean temperatures (Ellrod 1995). GOES visible imagery was converted to albedo (reflectivity) using prelaunch and postlaunch calibration methods published by the NOAA's National Environmental Satellite, Data, and Information Service (NESDIS). In the domain that is of greatest interest here, the vast majority of variation in albedo values is caused by variations in clouds, but albedo may be secondarily modified by other factors such as vegetation, snow, desert playas, water vapor, and aerosols (Iacobellis and Cayan 2013).

\subsubsection{Quantifying cloud cover}

To discriminate clouds from land and ocean surfaces, an empirical threshold was established by creating kernel density plots of albedos (Figure S1). Kernel density plots (using a Gaussian kernel type) of pixels covering land and ocean both showed skewed symmetric distributions. The initial part of both curves was bell shaped, which was inferred as the variability in surface reflectance owing to changes in solar angle and optical thickness of the atmosphere. We inferred the latter part of both representing a range in cloudiness. We selected a threshold (0.3) that was to the right of the bell-shaped portion of both curves. This threshold is also the same as that used by the ISCCP dataset to estimate cloud fraction from GOES imagery (Rossow and Schiffer 1991). To check if the same threshold was applicable to different times of the day and year, separate empirical cumulative distribution functions (ECDFS) of albedo over one pixel covering land and one covering the ocean surface were calculated (Figure S2). While surface reflectance varied with the angle of incoming solar radiation (i.e., time of day and month), this analysis indicated that the albedo threshold was not sensitive to changing solar geometry. Since summer clouds in this region are nearly exclusively low-lying marine stratus (Iacobellis and Cayan 2013), no attempt was made to screen higher, nonstratus clouds.

For each day of the satellite record, a map of cloud-cover fraction (CCF) was calculated, where CCF for a given pixel was the fraction of twice-hourly albedo values that exceeded 0.3 . For each day, we considered all images beginning $30 \mathrm{~min}$ after sunrise and ending $30 \mathrm{~min}$ before sunset to avoid low solar angles, when surfaces have higher albedos. The validity of satellite-derived CCF was supported by ground-based insolation measurements at two sites on Santa Cruz Island, where daily CCF values were strongly and negatively correlated with mean daily insolation totals (Figure 2). The two field sites (Sauces and Upem) are described in detail by Carbone et al. (2013). Daily CCF was aggregated to a monthly mean. To investigate the diurnal cycle of cloud cover, mean monthly CCF was also calculated for subdaily periods; mornings [sunrise, 1130 Pacific standard time (PST)], afternoons (1200-1530 PST), and evenings (1600 PST, sunset). Using this methodology another index of total monthly hours of cloud cover was also created.

\subsubsection{Mapping fog frequency}

We combined our calculations of CCF with a DEM to develop monthly estimates of the geographic distribution of fog inundation on Santa Cruz and Santa 
Earth Interactions - Volume 20 (2016) - Paper No. 15 • Page 7
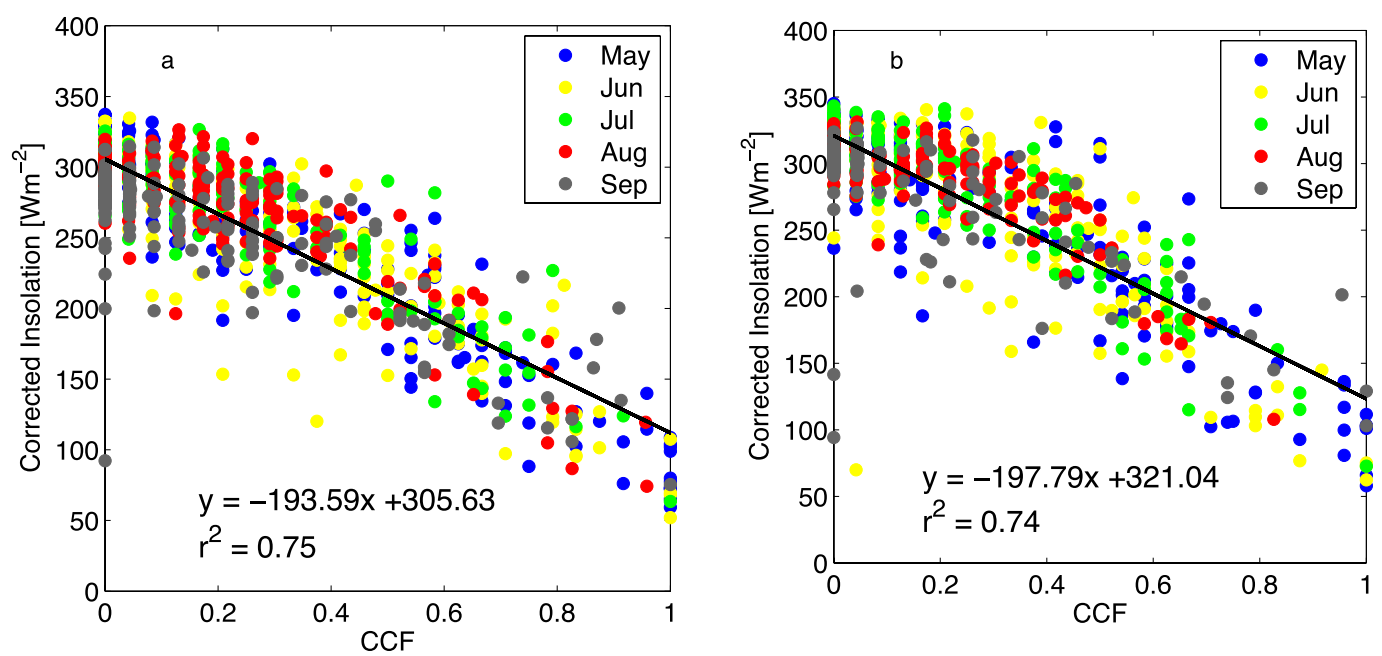

Figure 2. Daily CCF plotted against available daily insolation data at (a) Sauces and (b) Upem on Santa Cruz Island. Cloudier days from GOES correspond with reduced insolation. Insolation data were corrected by removing the effect of solar angle on mean daily insolation.

Rosa Islands. We calculated fog frequency at a given location for each month as the product of the $\mathrm{CCF}$ and the fraction of time spent below the cloud top and above the cloud base for that month. Because visible satellite imagery only indicates the locations of cloud tops, we used observations of cloud-base heights from a nearby airport to characterize the vertical distributions of cloud bottoms. The topography of the islands is highly variable, so we characterized fog inundation for a DEM with $100-\mathrm{m}$ spatial resolution. In the next two subsections, we describe the downscaling methodology and how we calculated the fraction of time below the cloud top and above the cloud bottom. A schematic of the methodological flow is provided in Figure 3.

2.2.3.1. Downscaled frequency of cloud cover. The maps of CCF indicate the fraction of time when the land or ocean surface is below a cloud top. At the relatively coarse 1-km resolution of the GOES imagery, however, much topographic detail regarding the intersection between the complex island topography and the cloud top is lost. Rather than using simple bilinear interpolation to downscale the 1-km CCF maps, a 100-m DEM was used in combination with nearby radiosonde-based measurements of marine layer depth to more realistically characterize how $\mathrm{CCF}$ should be vertically distributed throughout a given 1-km pixel.

The altitude of the top of the marine layer, and thus stratus cloud tops, is defined by the base of the atmospheric temperature inversion that caps the marine layer nearly continuously throughout summer. For a detailed description of the regional atmospheric profile of Southern California, readers are referred to Iacobellis et al. (2009). A vertical distribution of inversion-base heights was determined using twice-daily (0400 and 1600 PST) radiosonde (weather balloon) measurements of temperature throughout the atmospheric 
Earth Interactions - Volume 20 (2016) • Paper No. 15 • Page 8

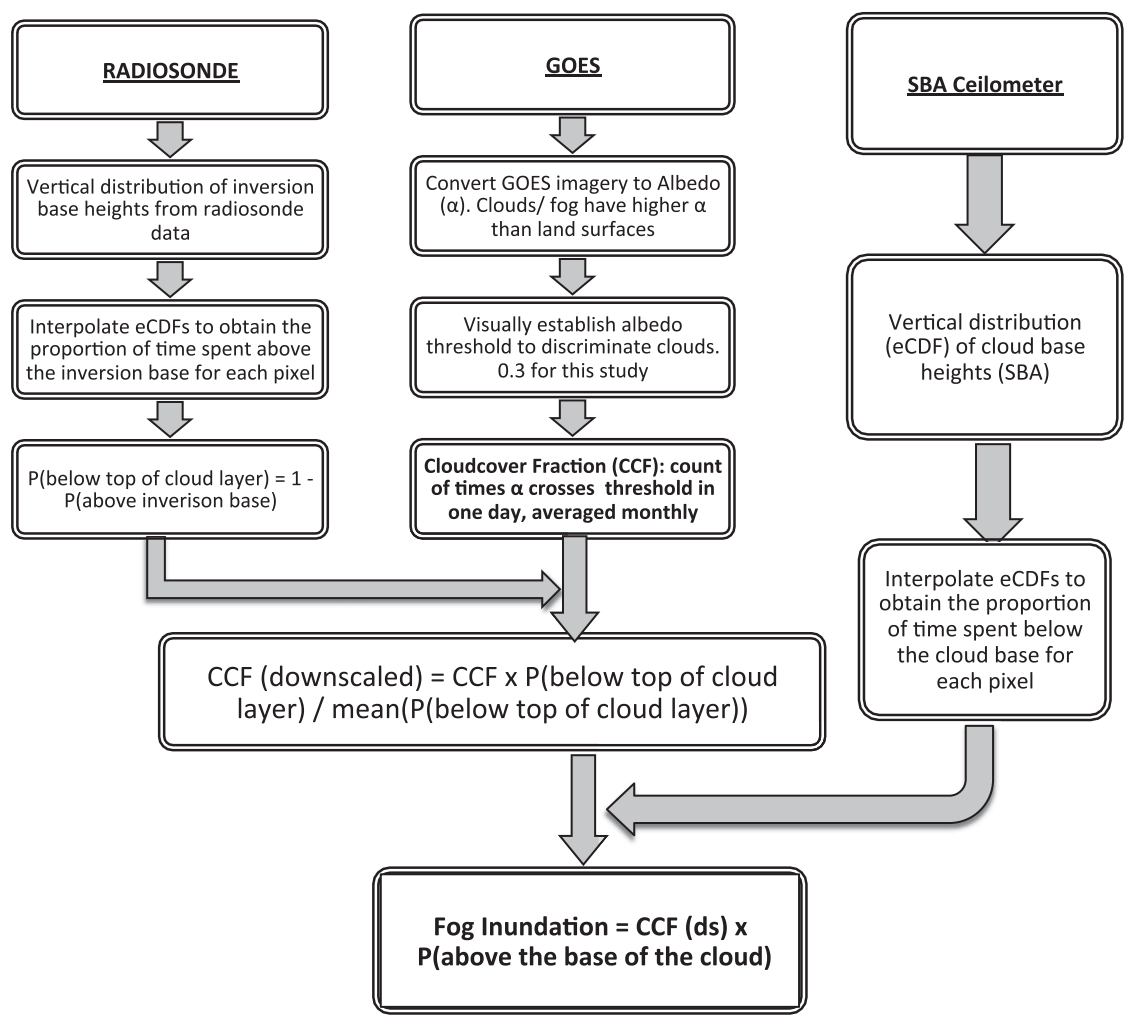

Figure 3. Algorithm for calculating monthly CCF and fog inundation.

profile. Radiosonde data came from San Diego Miramar (NKX; $289 \mathrm{~km}$ to the southeast of the northern Channel Islands) and Vandenberg Air Force Base (VAFB; $93 \mathrm{~km}$ to the northwest). Radiosonde data were accessed from Earth System Research Laboratory (ESRL) at NOAA (Schwartz and Govett 1992), and inversion-base heights were calculated by Iacobellis and Cayan (2013). The inversion base is generally $\sim 100 \mathrm{~m}$ lower at VAFB than NKX and morning inversion heights tend to be somewhat more variable than afternoon inversion heights but without much difference in the overall mean. For each month, we estimated the statistical distribution of cloud-top heights in our study region as the inverse distance-weighted mean of the ECDFs for NKX and VAFB during 1965-2012. The ECDFs of inversion-base heights for the two sites as well as that estimated for a point in the Santa Barbara Channel is shown in Figure S3a. The resulting ECDF (Islands in Figure S3) was calculated using both morning and evening data and was qualitatively more similar to the VAFB distribution (i.e., the mean of the resulting ECDF was closer to that for VAFB). This calculation assumes that there is a latitudinal gradient in inversion-base height between VAFB and KNKX. While inversions at the two locations are likely to be influenced by other environmental factors, this assumption was supported by investigating inversion-base heights calculated from the Modern-Era Retrospective Analysis for Research and Applications (MERRA) data from NASA's GEOS-5. MERRA ECDFs were calculated for the same three sites 


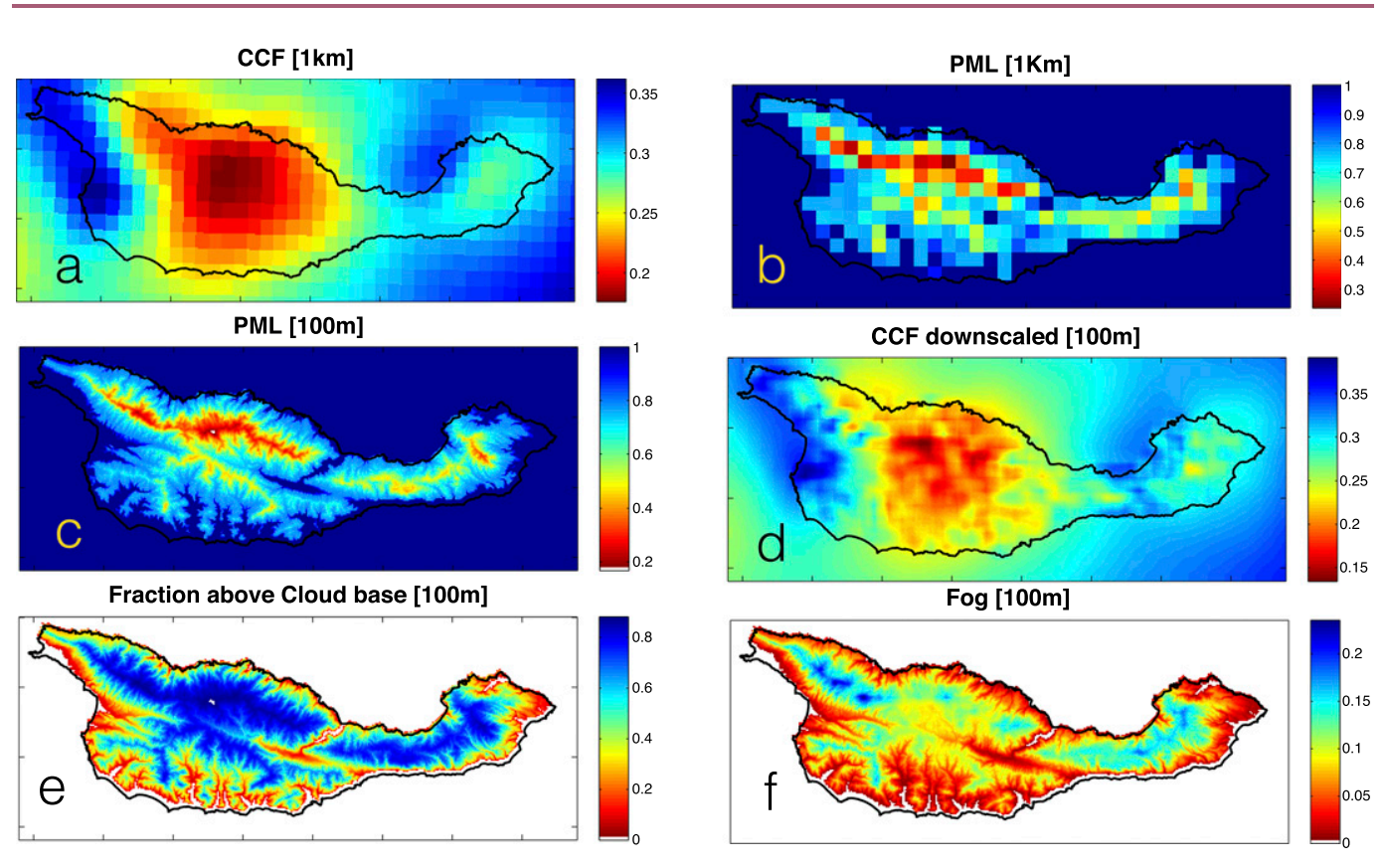

Figure 4. Downscaled fog inundation for $\mathrm{SCl}$ including all the intermediate stages. (a) GOES cloud cover at $1 \mathrm{~km}$. (b) Probability of pixels being within the marine layer (i.e., below inversion base; 1-km spatial resolution). (c) Probability of pixels being within the marine layer (i.e., below inversion base; 100-m spatial resolution). (d) Downscaled GOES cloud cover at $100-\mathrm{m}$ resolution. (e) Probability of pixels being above the cloud base at $100 \mathrm{~m}$. (f) Downscaled Fog inundation at $100-m$ resolution.

(VAFB, KNKX, and Islands). The shape of the MERRA inversion-base heights for the three points was nearly identical except for a difference in the mean, which decreased with increasing latitude (figure not shown). These modelbased results support the plausibility of the assumption that the distribution of inversion-base heights at the Islands is a distance-weighted mean of the distributions from KNKX and KVBG. It is noted, however, that there exist other more complex methods for estimating inversion-base or cloud-top heights (e.g., Sun-Mack et al. 2014), but for the purpose of this study, we feel that inversion-base heights obtained from radiosonde data are sufficient to characterize these processes within the Santa Barbara Channel.

Finally, these monthly ECDFs of inversion-base height were used to determine how the monthly CCF value for a given 1-km pixel should be distributed to more accurately represent the frequency of cloud cover at each of the 10000 center points on the 100-m DEM. To do this, we developed two elevation-dependent maps of the probability of being below the inversion base and therefore the probability of the land surface being within the marine layer (PML; Figures 4b,c). The end result was a downscaled version of CCF so that the average CCF of this version equaled the original GOES CCF, but with varying values that were organized in accordance with the probability distributions for being within the marine layer (Figure 4d): 


$$
\begin{aligned}
& \text { Earth Interactions } ・ \text { Volume } 20(2016) \cdot \text { Paper No. } 15 \cdot \text { Page } 10 \\
& \text { CCF100m }=\text { CCF1km } \times \frac{\text { PML100m }}{\text { PML1km }}
\end{aligned}
$$

2.2.3.2. Accounting for cloud-base height. To characterize the statistical distribution of cloud-base heights, we generated monthly ECDFs of cloud-base heights from Santa Barbara Airport (SBA; $30 \mathrm{~km}$ north) for mornings (sunrise, 1130 PST), afternoons (1200-1530 PST), and evenings (1600 PST, sunset; Figure S3b). Hourly measurements of cloud ceiling (called cloud base) heights are recorded at SBA and archived by the NOAA National Climatic Data Center (NCDC). The cloud base is defined by the NCDC as the height above ground level of the lowest cloud overhead when at least $5 / 8$ of the total sky is cloudy (NCDC 2008). Cloud-base heights were converted to meters above sea level. The monthly ECDFs of cloud-base heights served as a lookup table to estimate the vertical distribution of cloud-base heights for every $100-\mathrm{m}$ pixel of the DEM (Figure 4e).

The height of the cloud-base height is largely dependent on the near-surface dewpoint depression (e.g., Williams et al. 2015), which is the difference between the near-surface temperature and dewpoint. Since the dewpoint depression varies across the ocean surface it is unlikely that the height of the cloud base is the same across the channel. The dewpoint depression also shows significant spatial variation owing to differences in sensible versus latent heat fluxes that are heavily influenced by the surrounding environment (i.e., land vs ocean). During the day, the dewpoint depression increases going inland from the ocean surface (as the surface temperature increases), thereby causing spatial variations in cloud-base height that remain unaccounted for. This error is likely to be low in coastal areas but with the highest errors being observed at midlevel elevation, where the ECDF (Figure S3b) changes rapidly. Cloud-base heights are recorded at $30-\mathrm{m}$ vertical resolution and increase the uncertainty of the resulting fog frequency model.

To capture the gradient in surface temperature and relative humidity across the channel, high-resolution satellite-derived products (such as MODIS land surface temperature) as well as reanalysis products such as NARR surface relative humidity and dewpoint temperature can be used. However, climatologies of surface temperature are usually calculated from cloud-free satellite imagery and would lead to erroneous estimations of the lifting condensation level on days that experience stratus, which is the aim of this study. Moreover, little variation in dewpoint temperature was found for pixels covering land versus ocean across the channel using the NARR dataset.

Therefore, while cloud-base heights are indeed likely to vary across the Santa Barbara Channel, direct cloud-base height measurements at Santa Barbara Airport, which is less than $1 \mathrm{~km}$ from the coast, serve as the most viable proxy for cloudbase heights on the nearby island in the absence of direct meteorological measurements across the island and a more complex (but still difficult to validate) boundary layer modeling approach.

2.2.3.3. Fog frequency. Fog inundation for a given $100-\mathrm{m}$ pixel, or $\mathrm{Fog}_{100 \mathrm{~m}}$, was calculated as the joint probability of cloud cover at $100 \mathrm{~m}$ and the probability of being above the cloud-base height, that is, 


\section{Earth Interactions - Volume 20 (2016) • Paper No. 15 • Page 11 \\ Fog $100 \mathrm{~m}=\mathrm{CCF} 100 \mathrm{~m} \times \mathrm{CBH} 100 \mathrm{~m}$.}

Fog inundation was calculated for mornings, afternoons, and evenings and then averaged to a daily mean. Figure 4 illustrates the processes involved in calculating fog inundation, step by step.

It is important to note that this approach to estimate fog from stratus assumes independence between the GOES satellite imagery and the observations of inversion- and cloud-base heights. In reality, day-to-day variability in cloud-base height and inversion-base height is weakly and positively related, but the assumption of independence does not substantially affect these results since we are interested in fog inundation conditions averaged over relatively long time periods of months to years.

\section{Results and discussion}

\subsection{Spatial patterns of cloud cover}

The cloud-cover fraction averaged across the years 2001-12 shows a west-east gradient with the highest values in the west-northwest areas (Figure 5a) and can be attributed to patterns of wind direction (Dorman and Winant 2000) and SST (Otero and Siegel 2004; Harms and Winant 1998) in the Santa Barbara Channel. Prevailing northwesterly winds and cool SSTs lead to high cloud cover in the western Santa Barbara Channel and San Miguel Island. As stratus blows inland from the northwest, it is restricted by topography (Iacobellis and Cayan 2013; Fischer and Still 2007). Coastal ridges on the islands restrict expansion of stratus leading to a "fog shadow" effect (Garreaud et al. 2008) on the leeward sides of the three bigger islands. Easterly winds and the poleward-flowing California Countercurrent, bringing warmer waters from the south, influence the eastern and southern areas of the channel. The confluence of these surface currents leads to the formation of a cyclonic eddy in the Santa Barbara channel that entrains moisture and increases the probability of stratus formation (Dorman and Winant 2000). Cloud cover is lowest at high elevations on Santa Cruz Island. The eastwest trending range on the north side of the island is consistently above the base of the inversion and therefore cloud free. The ridge also restricts stratus movement in the central valley.

CCF was correlated with a previous estimate of stratus $(R=0.73, p<0.01)$ developed by Williams (2009) and Fischer et al. (2009) using NASA MODIS data (Terra overpass at 1030 PST for 2000-06 and a spatial resolution of $250 \mathrm{~m}$ ).

\subsection{Temporal patterns of cloud cover}

\subsubsection{Diurnal patterns}

The magnitude as well as extent of marine stratus is highest in the mornings and lowest in the afternoons (Figure 5b). Santa Cruz and Santa Rosa Islands are largely cloud free in the afternoons. In the evenings, clouds can be seen to develop on the coast on the windward sides of these islands, even as areas upwind are cloud free. This can be attributed to the convergence of surface wind as it approaches the 

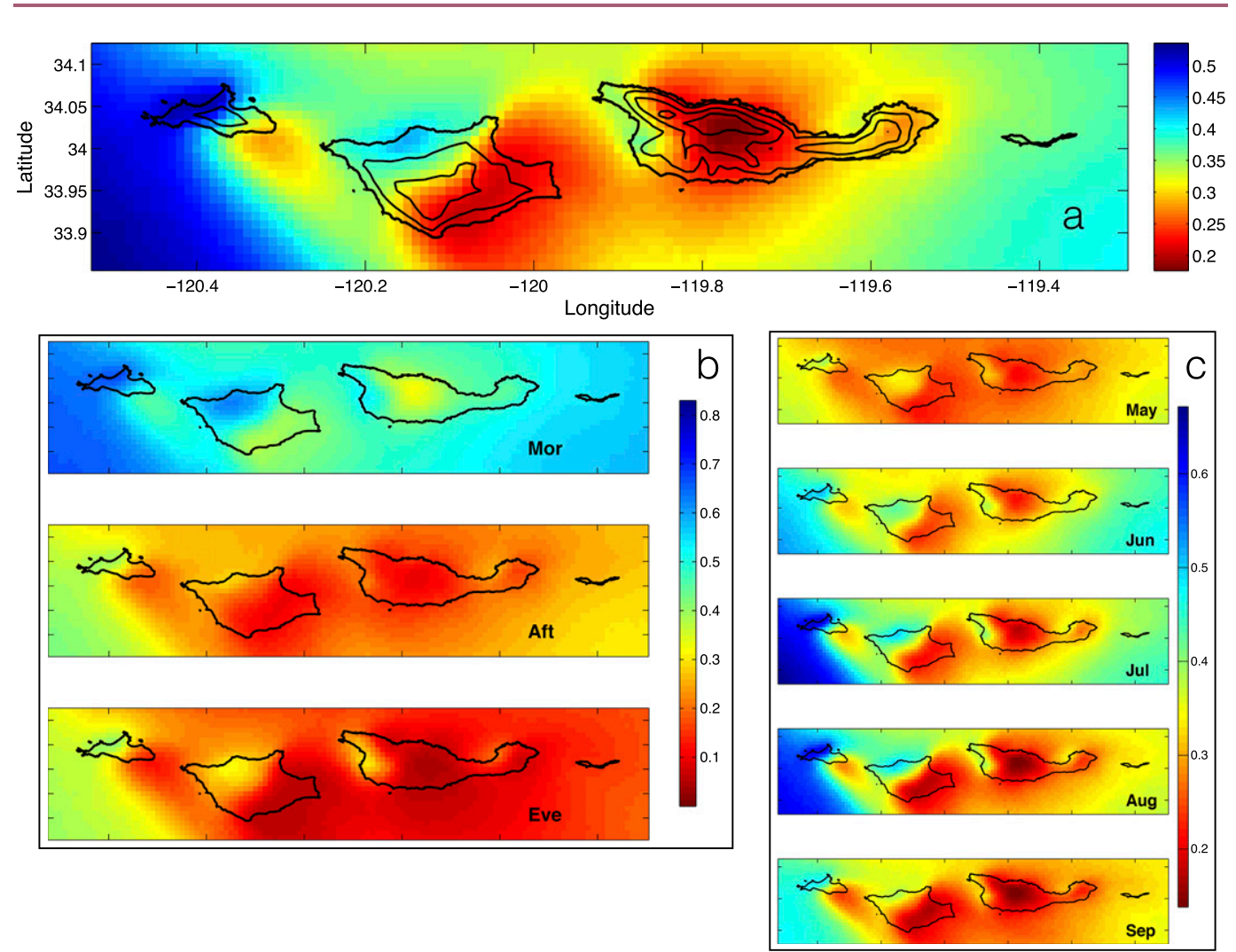

Figure 5. (a) Cloud-cover fraction map from GOES (1-km spatial resolution) for the northern Channel Islands for May-September, averaged for 2001-12. Elevation contours shown at 130,260 , and $390 \mathrm{~m}$ (above sea level). (b) Diurnal patterns of cloud cover shown for (top) mornings, (middle) afternoons, and (bottom) evenings and (c) monthly patterns.

island, leading to the lifting of surface air to the condensation level, resulting in cloud formation (Leipper 1994). It is likely that marine stratus often forms first at the sea-land interface in the evenings and is then advected inland. Moreover, there is a positive feedback for stratus formation as cloud surfaces provide increased condensation nuclei (Filonczuk et al. 1995). Cloud formation can also take place throughout the night and into the predawn morning hours as a result of mixing between a developed land breeze and alongshore marine flows (Koračin et al. 2005). As there are few drivers for cloud dissipation at night and cloud cover is high during the morning, it is highly probable that nighttime cloud cover is also high, although we cannot quantify nighttime cloud cover with visible satellite albedo data.

\subsubsection{Seasonality and interannual variability}

Across months, cloud cover is lowest in May, peaks in July, and then decreases in September (Figure 5c). The seasonal cycle can be explained by examining the height of the inversion base, which shows a complementary cycle (Figure S4). Low 
inversion base promotes stratus formation but at the same time prevents stratus from crossing high elevation ridgelines. This can be best seen on Santa Cruz Island where a low inversion base restricts clouds occurrence over high ridgelines (dark red areas in Figure 5c) beginning in July. While cloud cover across the scene is highest in July, CCF in these areas is very low. Interannual variability for the 12 years is highest in the month of May followed by September and lowest in July (figure not shown). On the islands, interannual variability is low over areas that are cloudy most often, indicating that the patterns of cloud cover are consistent spatially and temporally across the years studied.

\subsection{Spatial and temporal patterns of fog inundation}

Mean morning fog inundation over Santa Cruz and Santa Rosa Islands for the months of May-September is shown in Figure 6a. While cloud-cover occurrence is dependent on elevation barriers and coupled atmosphere-ocean eddy formation, fog inundation within cloudy areas follows an elevation gradient. As stratus extends inland, the probability of surface contact increases. The expansion of stratus is constrained by the inversion base, which is often lower than the highest areas on the islands. On Santa Rosa Island, stratus is often able to orographically lift over ridgelines, leading to fog immersion in the leeward areas (light green areas in Figure 6a in the eastern part of the island). On Santa Cruz Island, fog is highest on the windward slopes of the ridges (green and blue areas on western SCI). Large parts of the island including the central valley are virtually always fog free.

Diurnally, fog inundation is highest in the mornings (Figure 6b). As the land warms up during the day, fog dissipates and is almost nonexistent in the afternoons. In the evening stratus develops and fog starts to roll in.

The monthly cycle of fog on both islands is similar to the patterns of marine stratus (Figure 6c; for comparison with cloud cover, see Figure 5c). July and August are the foggiest months, while May is the least foggy, followed by September.

It is important to note that the minimum cloud-base height as recorded at Santa Barbara Airport throughout the study period was $21.1 \mathrm{~m}$, which leads to an underestimation of fog inundation, particularly in low-lying coastal areas, which are classified as fog free. While low elevation coastal areas may experience high stratus frequency, previous studies on Santa Cruz Island found very low fog water deposition (implying low fog frequency) in these areas (Fischer and Still 2007; Fischer et al. 2009).

\section{Comparison with fog drip data}

We compared our estimates of monthly cloud cover and fog inundation with fog drip data collected on Santa Cruz Island (Sauces; see Fischer and Still 2007; Carbone et al. 2013) between the years 2005 and 2011. Sauces is located on the western ridge of Santa Cruz Island, at an elevation of $296 \mathrm{~m}$ a within a stand of endemic bishop pine trees. The seasonal patterns of total drip collected were similar to those of satellite-estimated patterns of stratus, with the highest dip amounts collected during midsummer and lower total volumes during the months of May and September. Similar to observed dynamics of cloud cover and fog, interannual variability of fog drip was found to be the highest in May. 

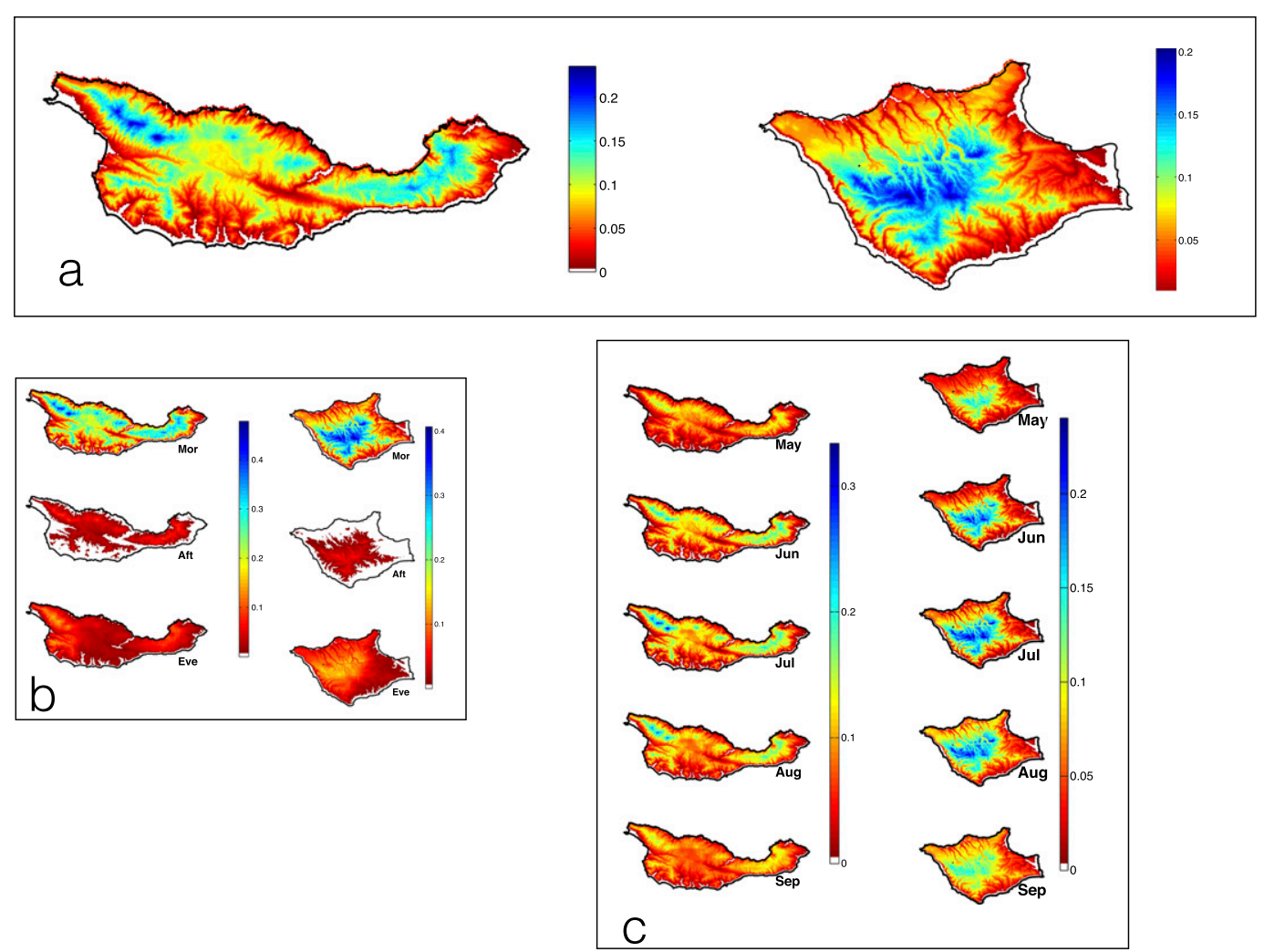

Figure 6. (a) Mean fog inundation (100 m) for (left) Santa Cruz and (right) Santa Rosa Islands. This represents the probability of fog inundation (section 2.2.3.3) for the months of May-September, across the years 2001-12, on the two islands. (b) Diurnal patterns of fog inundation and (c) monthly patterns.

Indexes of monthly total hours of cloud cover and fog inundation for pixels covering these sites were calculated. An index of total overcast (or nonfog cloud) hours was calculated as the difference between total cloud hours and total fog hours. Model 2 regression (Ricker 1973) was performed on the total volumes of fog drip and these three variables (cloud hours, fog hours, and overcast hours; Figure 7). Fog drip was found to be positively and significantly correlated with all variables. Fog inundation was found to be the best predictor for fog drip, while the total hours of overcast was the worst predictor of fog drip. Bootstrapping analysis, however, revealed overlap between the $95 \%$ confidence intervals for the reported regression coefficients. The regression analyses were repeated using an index of hours that received fog drip instead of fog drip volumes. The results of these regressions were not significantly different from using fog drip alone. In this study, we were able to generate monthly scale patterns of stratus across the islands. However, our approach did not let us model the intensity or duration of individual fog events, which strongly control the volume of drip collected. In addition to the spatial and temporal patterns of stratus, the total volume of fog drip is a function of the droplet size distribution in the cloud, wind speed, and the vegetative cover present at the site. Fog drip is strongly dependent on the height of the cloud base, 



Figure 7. Geometric regression of measured fog drip with measured fog drip at Sauces on Santa Cruz Island against satellite-derived estimates of (a) monthly total hours of cloud cover, (b) hours of fog inundation, and an (c) index of monthly hours of overcast (or nonfog cloud defined as the difference between cloud cover and hours of fog).

which is likely to be different at the site of data collection from the Santa Barbara Airport (where information on the cloud-base height is collected; see section 2.2.3.2). Given these discrepancies, and the differences in the spatial resolution of satellite data versus a point measurement of fog drip data, discriminating fog from cloud cover improved the ability to predict fog drip. However, more long-term datasets from the northern Channel Islands are required to perform a thorough validation.

\section{Implications for terrestriall ecology}

Summertime marine stratus on the Channel Islands has been shown to add considerable amounts of water to the semiarid ecosystem (Fischer and Still 2007) and influence tree growth (Williams et al. 2008) and ecosystem carbon cycling (Carbone et al. 2011). Santa Cruz and Santa Rosa Islands host the southernmost stands of endemic bishop pine trees (Pinus muricata) in the United States. These trees occur along a stratus gradient and are known to inhabit mid- to high elevation areas where the likelihood of stratus being intercepted by vegetation is high. A more recent study found that the risk of drought-induced mortality of bishop pines on Santa Cruz Island is lower in foggier areas on the island (Baguskas et al. 2014). Fog water is especially important for saplings (Baguskas et al. 2016) and sapling survival will determine if trees will continue to inhabit the islands following huge die-offs as a result of the extreme 2013/14 drought in California (S. A. Baguskas 2015, personal communication). Moreover, defoliated dead tree canopies offer little surface area for fog droplets to coalesce, therefore greatly impacting the amount of water entering the ecosystem. Similarly, on Santa Rosa Island, remnant stands of the endemic island oak (Quercus tomentella Engelm.) inhabit ridgetop areas within the stratus layer, and the Santa Rosa Island Torrey pine stand occurs where overcast stratus persists through the summer months (Williams et al. 2008).

While nights spent immersed in fog provide water that may be used by plants to maintain water status, cloudy and foggy mornings decrease the total heat load and 
Earth Interactions - Volume 20 (2016) • Paper No. 15 • Page 16

evaporative demand and increase the diffused fraction of sunlight, facilitating photosynthesis at low water costs. By the afternoon, trees may close their stomata to prevent transpirative water losses and thus be less affected by decreased cloud cover. Seasonally, stratus provides relief from otherwise dry and hot summers and may provide a buffer until the onset of winter rainfall.

A novel method was developed to discriminate and downscale spatiotemporal patterns of fog from those of stratus. Fog drip data appeared to support this method. Knowing the patterns of area intercepted by fog is a key component of estimating direct fog drip into the ecosystem. Moreover, a climatology of fog across meaningful ecological spatial and temporal scales was developed. On Santa Cruz Island, these results can be used to help stratify sampling of the pines across the stand for population modeling to estimate bishop pine persistence in the future. This analysis can be extended to areas along the western coast of the United States and other areas to map fogecosystem interactions.

These results have implications for the recovery of terrestrial ecosystems on the northern Channel Islands. The islands are rebounding from more than a century of ranching-related land use that resulted in islandwide conversion of land cover from shrub and woodlands to barren and annual grassland (McEachern et al. 2015). Preranching patterns are obscure, but recovery of native vegetation appears most advanced in cloudy and foggy areas. For example, oak acorns require continuous moisture in order to germinate; if they dry out, the seedling embryo will die. Thus, regeneration of upland oak stands depends on fog moisture to maintain adequate seedbed conditions for germination. Similarly, fog drip (Carbone et al. 2013) maintains the soil moisture necessary for seedling growth through the summer drought. Results of this modeling effort can be used to predict areas where such passive recovery may be sufficient to restore island ecosystem functions, allowing land managers to direct resources to areas less likely to benefit from the recurring presence of atmospheric moisture where heat load and evapotranspiration place greater stress on recovering vegetation. Patterns of stratus on forested parts of western Santa Cruz Island correlate strongly and significantly with large areas of Santa Rosa (figure not shown), where restoration efforts are beginning. Examining the forest structure and species composition of the forested areas on Santa Cruz can inform restoration strategies for Santa Rosa Island.

Acknowledgments. This work was funded by grants from "Save the Redwoods League" and the USGS awarded to Chris Still (PI). We thank Bodo Bookhagen and John Potapenko for providing the LiDAR datasets and Alicia Torregrosa for comments on the manuscript.

\section{References}

Baguskas, S. A., S. H. Peterson, B. Bookhagen, and C. J. Still, 2014: Evaluating spatial patterns of drought-induced tree mortality in a coastal California pine forest. For. Ecol. Manage., 315, 43-53, doi:10.1016/j.foreco.2013.12.020.

— C. J. Still, D. T. Fischer, C. M. D’Antonio, and J. Y. King, 2016: Coastal fog during summer drought improves the water status of sapling trees more than adult trees in a California pine forest. Oecologia, doi:10.1007/s00442-016-3556-y, in press. 
Earth Interactions - Volume 20 (2016) • Paper No. 15 • Page 17

Baldocchi, D., and E. Waller, 2014: Winter fog is decreasing in the fruit growing region of the Central Valley of California. Geophys. Res. Lett., 41, 3251-3256, doi:10.1002/2014GL060018.

Bendix, J., B. Thies, T. Nauß, and J. Cermak, 2006: A feasibility study of daytime fog and low stratus detection with TERRA/AQUA-MODIS over land. Meteor. Appl., 13, 111-125, doi:10.1017/S1350482706002180.

Burgess, S. S. O., and T. E. Dawson, 2004: The contribution of fog to the water relations of Sequoia sempervirens (D. Don): Foliar uptake and prevention of dehydration. Plant Cell Environ., 27, 1023-1024, doi:10.1111/j.1365-3040.2004.01207.x.

Carbone, M. S., C. J. Still, A. R. Ambrose, T. E. Dawson, A. P. Williams, C. M. Boot, and J. P. Schimel, 2011: Seasonal and episodic moisture controls on plant and microbial contributions to soil respiration. Oecologia, 167, 265-278, doi:10.1007/s00442-011-1975-3.

— , A. Park Williams, A. R. Ambrose, C. M. Boot, E. S. Bradley, T. E. Dawson, and C. J. Still, 2013: Cloud shading and fog drip influence the metabolism of a coastal pine ecosystem. Global Change Biol., 19, 484-497, doi:10.1111/gcb.12054.

Cereceda, P., H. Larrain, P. Osses, M. Farías, and I. Egaña, 2008: The climate of the coast and fog zone in the Tarapaca region, Atacama Desert, Chile. Atmos. Res., 87, 301-311, doi:10.1016/ j.atmosres.2007.11.011.

Chaurasia, S., V. Sathiyamoorthy, B. Paul Shukla, B. Simon, P. C. Joshi, and P. K. Pal, 2011: Night time fog detection using MODIS data over northern India. Meteor. Appl., 18, 483-494, doi:10.1002/met.248.

Dawson, T. E., 1998: Fog in the California redwood forest: Ecosystem inputs and use by plants. Oecologia, 117, 476-485, doi:10.1007/s004420050683.

Deng, J., J. Bai, and J. Liu, 2006: Detection of daytime fog using MODIS multispectral data. Meteor. Sci. Technol., 34, 188-193.

Dorman, C. E., and C. D. Winant, 2000: The structure and variability of the marine atmosphere around the Santa Barbara Channel. Mon. Wea. Rev., 128, 261-282, doi:10.1175/ 1520-0493(2000)128<0261:TSAVOT>2.0.CO;2.

Eller, C. B., A. L. Lima, and R. S. Oliveira, 2013: Foliar uptake of fog water and transport belowground alleviates drought effects in the cloud forest tree species, Drimys brasiliensis (Winteraceae). New Phytol., 199, 151-162, doi:10.1111/nph.12248.

Ellrod, G. P., 1995: Advances in the detection and analysis of fog at night using GOES multispectral infrared imagery. Wea. Forecasting, 10, 606-619, doi:10.1175/1520-0434(1995)010<0606: AITDAA $>2.0 . \mathrm{CO} ; 2$.

Filonczuk, M. K., D. R. Cayan, and L. G. Riddle, 1995: Variability of marine fog along the California coast. Climate Research Division, Scripps Institution of Oceanography, University of California, San Diego, SIO Reference 95-2, 102 pp.

Fischer, D. T., and C. J. Still, 2007: Evaluating patterns of fog water deposition and isotopic composition on the California Channel Islands. Water Resour. Res., 43, W04420, doi:10.1029/2006WR005124.

— — _ - and A. P. Williams, 2009: Significance of summer fog and overcast for drought stress and ecological functioning of coastal California endemic plant species. J. Biogeogr., 36, 783799, doi:10.1111/j.1365-2699.2008.02025.x.

Garreaud, R., J. Barichivich, D. A. Christie, and A. Maldonado, 2008: Interannual variability of the coastal fog at Fray Jorge relict forests in semiarid Chile. J. Geophys. Res., 113, G04011, doi:10.1029/2008JG000709.

Gultepe, I., R. Tardif, S. C. Michaelides, J. Cermak, A. Bott, J. Bendix, and S. G. Cober, 2007: Fog research: A review of past achievements and future perspectives. Pure Appl. Geophys., 164, 1121-1159, doi:10.1007/s00024-007-0211-x.

Harms, S., and C. D. Winant, 1998: Characteristic patterns of the circulation in the Santa Barbara Channel. J. Geophys. Res., 103, 3041-3065, doi:10.1029/97JC02393.

Iacobellis, S. F., and D. R. Cayan, 2013: The variability of California summertime marine stratus: Impacts on surface air temperatures. J. Geophys. Res. Atmos., 118, 9105-9122, doi:10.1002/jgrd.50652. 
Earth Interactions - Volume 20 (2016) • Paper No. 15 • Page 18

— J. R. Norris, M. Kanamitsu, M. Tyree, and D. R. Cayan, 2009: Climate variability and California low-level temperature inversions. California Climate Change Center Final Paper CEC-500-2009-020-F, 48 pp. [Available online at http://www.energy.ca.gov/2009publications/ CEC-500-2009-020/CEC-500-2009-020-F.PDF.]

Johnstone, J. A., and T. E. Dawson, 2010: Climatic context and ecological implications of summer fog decline in the coast redwood region. Proc. Natl. Acad. Sci. USA, 107, 4533-4538, doi:10.1073/pnas.0915062107.

Junak, S., T. Ayers, R. Scott, D. Wilken, and D. A. Young, 1995: A Flora of Santa Cruz Island. California Native Plant Society, 397 pp.

Koračin, D., J. A. Businger, C. E. Dorman, and J. M. Lewis, 2005: Formation, evolution, and dissipation of coastal sea fog. Bound.-Layer Meteor, 117, 447-478, doi:10.1007/s10546-005-2772-5.

— C. E. Dorman, J. M. Lewis, J. G. Hudson, E. M. Wilcox, and A. Torregrosa, 2014: Marine fog: A review. Atmos. Res., 143, 142-175, doi:10.1016/j.atmosres.2013.12.012.

Kupfer, J. A., and D. M. Cairns, 1996: The suitability of montane ecotones as indicators of global climatic change. Prog. Phys. Geogr., 20, 253-272, doi:10.1177/030913339602000301.

Leipper, D. F., 1994: Fog on the U.S. West Coast: A review. Bull. Amer. Meteor. Soc., 75, 229-240, doi:10.1175/1520-0477(1994)075<0229:FOTUWC >2.0.CO;2.

Limm, E. B., K. A. Simonin, A. G. Bothman, and T. E. Dawson, 2009: Foliar water uptake: A common water acquisition strategy for plants of the redwood forest. Oecologia, 161, 449459, doi:10.1007/s00442-009-1400-3.

McEachern, K., T. Atwater, P. Collins, K. Faulkner and D. Richards, 2015: Managed island ecosystems. Ecosystems of California, H. Mooney and E. Zavaleta, Eds., University of California Press, 755-778.

Moody, A., 2000: Analysis of plant species diversity with respect to island characteristics on the Channel Islands, California. J. Biogeogr., 27, 711-723, doi:10.1046/j.1365-2699.2000.00435.x.

NCDC, 2008: Federal climate complex data documentation for integrated surface data. National Climatic Data Center Rep., 133 pp. [Available online at http://www1.ncdc.noaa.gov/pub/ data/ish/ish-format-document.pdf.]

Noss, R. F., 1999: The Redwood Forest: History, Ecology, and Conservation of the Coast Redwoods. Island Press, $366 \mathrm{pp}$.

Otero, M. P., and D. A. Siegel, 2004: Spatial and temporal characteristics of sediment plumes and phytoplankton blooms in the Santa Barbara Channel. Deep-Sea Res. II, 51, 1129-1149, doi:10.1016/S0967-0645(04)00104-3.

Ricker, W. E., 1973: Linear regressions in fishery research. J. Fish. Res. Board Can., 30, 409-434, doi:10.1139/f73-072.

Rossow, W. B., and R. A. Schiffer, 1991: ISCCP cloud data products. Bull. Amer. Meteor. Soc., 72, 2-20, doi:10.1175/1520-0477(1991)072<0002:ICDP>2.0.CO;2.

Schwartz, B., and M. Govett, 1992: A hydrostatically consistent North American radiosonde data base at the Forecast Systems Laboratory, 1946-present. NOAA Tech. Memo. ERL FSL-4, 88 pp. [Available online at http://www.esrl.noaa.gov/raobs/intl/radiosonde.pdf.]

Schwartz, R. E., A. Gershunov, S. F. Iacobellis, and D. R. Cayan, 2014: North American west coast summer low cloudiness: Broadscale variability associated with sea surface temperature. Geophys. Res. Lett., 41, 3307-3314, doi:10.1002/2014GL059825.

Still, C. J., P. N. Foster, and S. H. Schneider, 1999: Simulating the effects of climate change on tropical montane cloud forests. Nature, 398, 608-610, doi:10.1038/19293.

Sun-Mack, S., P. Minnis, Y. Chen, S. Kato, Y. Yi, S. C. Gibson, P. W. Heck, and D. M. Winker, 2014: Regional apparent boundary layer lapse rates determined from CALIPSO and MODIS data for cloud-height determination. J. Appl. Meteor. Climatol., 53, 990-1011, doi:10.1175/ JAMC-D-13-081.1.

Williams, A. P., 2009: Tree rings, climate variability, and coastal summer stratus clouds in the western United States. Ph.D. dissertation, University of California, Santa Barbara, 212 pp. 
Earth Interactions • Volume 20 (2016) • Paper No. 15 • Page 19

C. J. Still, D. T. Fischer, and S. W. Leavitt, 2008: The influence of summertime fog and overcast clouds on the growth of a coastal Californian pine: A tree-ring study. Oecologia, 156, 601-611, doi:10.1007/s00442-008-1025-y.

—, R. E. Schwartz, S. Iacobellis, R. Seager, B. I. Cook, C. J. Still, G. Husak, and J. Michaelsen, 2015: Urbanization causes increased cloud base height and decreased fog in coastal Southern California. Geophys. Res. Lett., 42, 1527-1536, doi:10.1002/2015GL063266.

Earth Interactions is published jointly by the American Meteorological Society, the American Geophysical Union, and the Association of American Geographers. Permission to use figures, tables, and brief excerpts from this journal in scientific and educational works is hereby granted provided that the source is acknowledged. Any use of material in this journal that is determined to be "fair use" under Section 107 or that satisfies the conditions specified in Section 108 of the U.S. Copyright Law (17 USC, as revised by P.IL. 94553) does not require the publishers' permission. For permission for any other from of copying, contact one of the copublishing societies. 